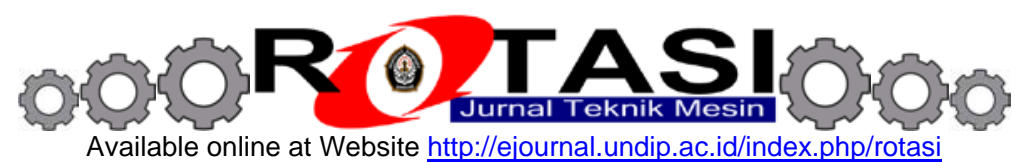

\title{
Pengaruh Tinggi Patahan Jalan dan Kecepatan Kendaraan Terhadap Potensi Cedera Tulang Belakang Pada Pengendara Sepeda Motor
}

\author{
*Norman Iskandar, Ikhsan Muhammad R. \\ Departemen Teknik Mesin, Fakultas Teknik, Universitas Diponegoro \\ Jl. Prof. Soedarto SH, Tembalang, Semarang 50275 Indonesia, Telp/Fax: +62 247460059 \\ *E-mail: norman.mesin@gmail.com
}

\begin{abstract}
Abstrak
Cedera tulang belakang (spinal cord injury) adalah kondisi medis yang sering dialami terutama oleh pengendara kendaraan bermotor roda dua. Cedera ini terjadi akibat adanya beban hantaman pada stuktur tulang belakang, maupun berupa pembebanan yang berulang dan fluktuatif. Penyebab kondisi ini pada pengendara sepeda motor bisa berasal dari gaya dan posisi mengemudi, dapat juga disebabkan oleh kondisi eksternal berupa adanya patahan jalan dan tingkat kecepatan. Jurnal ini dibuat untuk mencari tahu bagaimana pengaruh tinggi patahan jalan dan kecepatan sepeda motor terhadap risiko cedera tulang belakang melalui seberapa besar gaya reaksi dan beban yang ditimbulkan pada kondisi mengemudi tersebut. Hasil yang didapat adalah adanya gaya sebesar 452 N hingga 611.84 N. Dengan struktur tulang belakang yang mampu menahan gaya $650 \mathrm{~N}$ hingga $6431 \mathrm{~N}$ tergantung faktor kesehatan tulang. Juga, kemungkinan adanya kegagalan lelah akibat pembebanan berulang dan terus-menerus meningkatkan risiko bahaya terjadinya cedera tulang belakang.
\end{abstract}

Kata kunci: spinal cord injury, patahan jalan, gaya reaksi

\section{Pendahuluan}

Jalur transportasi di Kota Semarang memiliki kendala yaitu adanya potensi rob dan banjir yang sering menggenangi selama musim pasang dan musim hujan. Hal ini terjadi di wilayah utara Kota Semarang. Selain rob dan banjir, pada wilayah selatan atau Kota Semarang bagian atas memiliki permasalahan pada akses jalan utama yaitu rawan terjadi patahan. Hal ini seperti terlihat di jalan gombel lama, jalan menunju arah Gunung pati, Jalan di sekitar Kampus Unika Soegijopranoto dan jalan penghumbung area bawah dan atas di Kecamatan Tembalang yaitu di jalan sigar bencah.

Sama seperti rob dan banjir, patahan pada jalan merupakan salah satu penyebab meningkatnya potensi terjadinya kecelakaan dan potensi memperpendek umur kendaraan. Posisi kaki-kaki pada kendaraan terutama sistem suspensi menjadi bagian yang paling sering terkena imbas dari kondisi jalan seperti ini. Jika diabaikan maka kerusakan kendaraan akan semakin parah dan bisa berimbas kepada rangka kendaraan. Velg roda juga termasuk bagian yang cukup sering menjadi korban kondisi jalan yang penuh patahan. Selain komponen yang berkontak langsung dengan jalan, beberapa komponen lain di body kendaraan bisa pecah atau kendor jika setiap hari harus menerima goncangan akibat medan yang kurang baik ini. Sistim kelistrikan dan lampu juga lebih rentan bermasalah dan berumur pendek.

Patahan pada jalan selain berpotensi menyebabkan kejadian fatal seperti kecelakaan sebenarnya memiliki potensi menjadi sumber utama munculnya cedera tulang belakang pada para pengendara yang sering melewati jalan tersebut meskipun sang pengendara merasa tidak pernah sampai mengalami kecelakaan fatal. Sebagaimana diungkapkan oleh dr Luthfi Gatam, SpOT pada tahun 2012 bahwa selain bahaya kecelakaan, bahaya lain saat naik motor adalah fibrasi dan getaran dan benda apapaun jika digetarkan secara terus menerus maka bisa mengalami sobek atau kerusakan, termasuk tulang belakang [1].

NSCISC - National Spinal Cord Injury Statistical Center, merilis bahwa rata rata tiap tahun bertambah jumlah kasus tentang cedera tulang belakang dimana penyebab utamanya adalah kecelakaan kendaraan bermotor. Data laporan NSCISC bisa dilihat pada Gambar 1 [2].

Masalah yang lebih serius akibat dari sering berkendara apalagi ditunjang medan yang tidak baik adalah terjadinya apa yang termasuk dalam kategori trauma kinematika pada tulang belakang atau juga bisa sampai cedera pada tulang belakang yang di istilahkan dengan SCI - spinal cord injury. Ilustrasi dari SCI bisa dilihat pada Gambar 2 [3]. Efek benturan akibat hentakan yang tidak semuanya teredam oleh suspensi dan busa tempat duduk di kendaraan akan diteruskan sebagai beban kejut pada tulang belakang pengendara. Meskipun dalam susunan tulang belakang manusia sudah memiliki konsep peredaman terhadap beban kejut seperti terlihat pada Gambar 3. Kondisi kerja dari tulang belakang inipun masih sangat tergantung dengan kondisi dari tulang belakang tersebut, misal dari usianya serta kesiapannya dalam menerima beban kejut.

Kondisi umur, posisi sebagai pengemudi yang siap dengan refleknya dan pembonceng yang sering tidak siap dengan kondisinya apaalgi ditunjang seperti posisi duduk yang menyamping termasuk yang berpengaruh terhadap kinerja tulang belakang dalam menerima beban kejut dari bawah. Selain itu jika pengendara membawa beban dalam 
Norman Iskandar \& Ikhsan Muhammad R., Pengaruh Tinggi Patahan Jalan dan Kecepatan Kendaraan Terhadap Potensi Cedera Tulang Belakang Pada Pengendara Sepeda Motor

tas ransel yang cukup berat juga akan mempengaruhi kerja tulang belakang dalam merespon beban yang diberikan kepadanya.

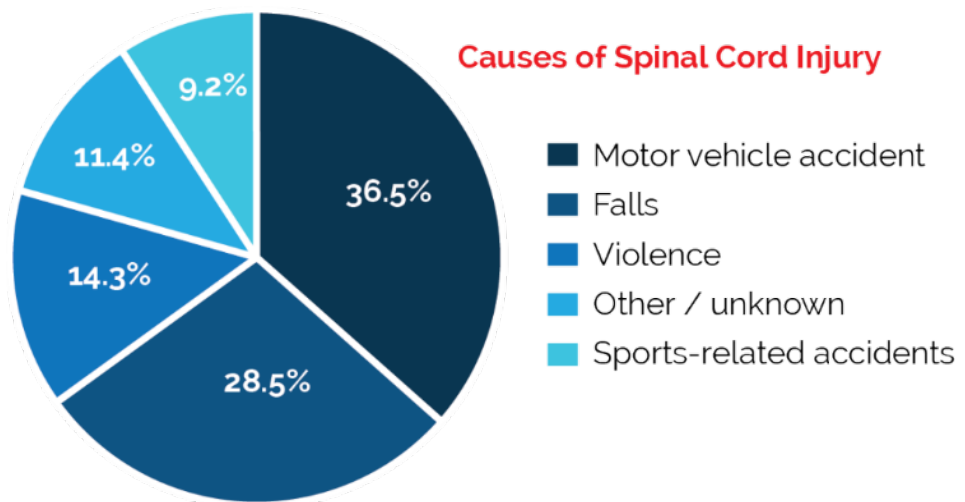

Gambar 1. Data dari NSCISC tentang penyebab cedera tulang belakang [4].
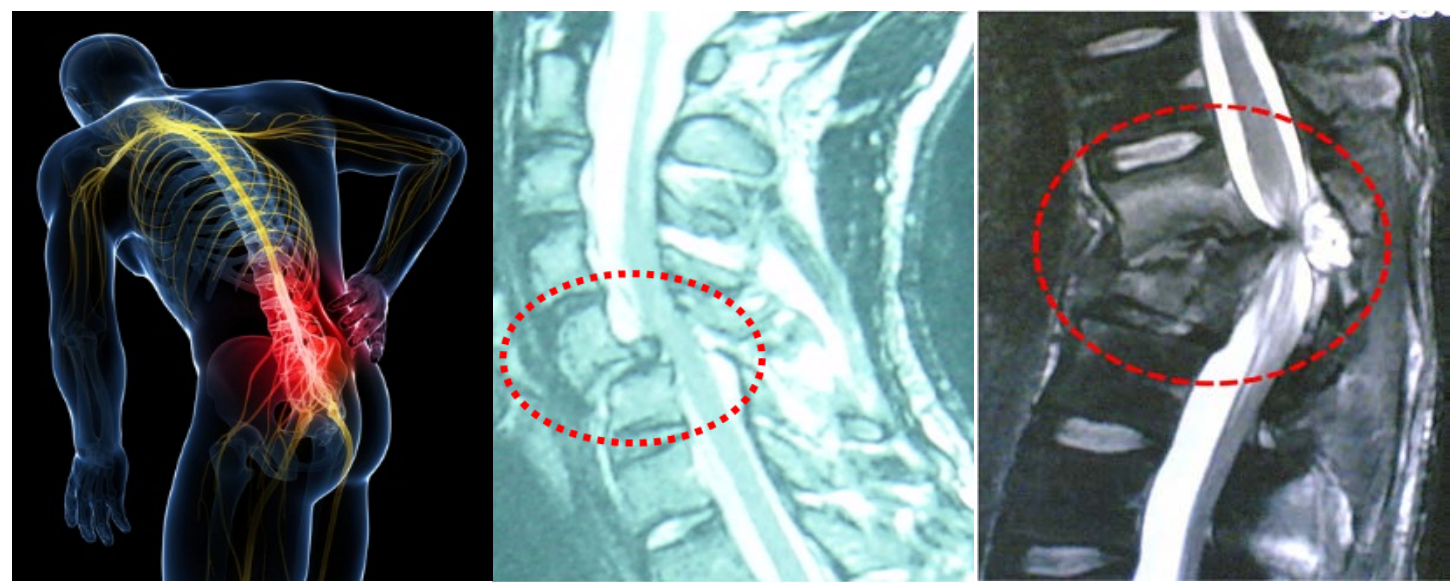

Gambar 2. Spinal Cord Injury-SCI [5].

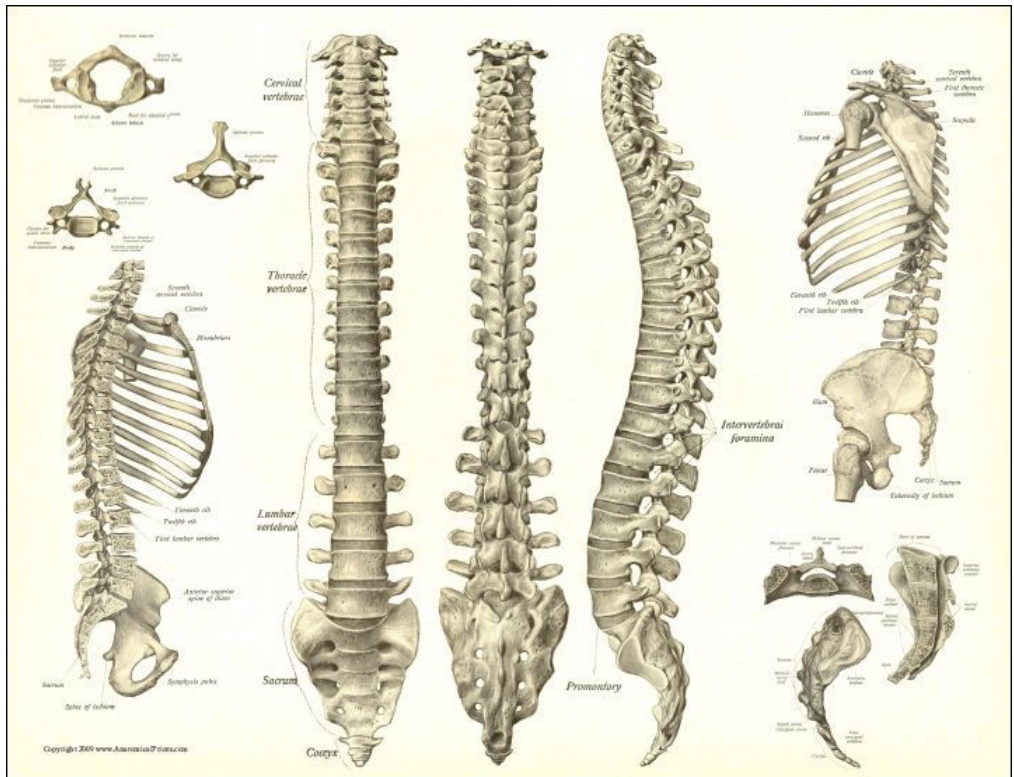

Gambar 3. Susunan tulang belakang manusia [3].

Bisa dilihat bahwa jalur yang memiliki tingkat patahan tinggi di Kota Semarang tersebut merupakan jalur padat yang dilewati segala usia karena merupakan akses utama untuk jalur pendidikan/sekolah dan kampus, jalur ekonomi seperti pasar serta akses perkantoran. Dari sisi moda transportasi maka jalur tersebut sebagian besar dominan dengan pengguna kendaraan berupa sepeda motor termasuk yang berboncengan. Untuk profil patahan bisa dilihat seperti pada Gambar 4 contoh patahan di jalan gombel lama. Profil patahan yang banyak ditemui adalah berupa patahan melintang 
di jalan sehingga seperti memotong jalan, meskipun diarea menuju Gunung pati sebagian segmen jalan terlihat profil patahan berbentuk sejajar arah jalan sehingga membuat celah dijalan yang arahnya memanjang searah jalan. Dari sisi suspensi kendaraan, profil suspensi yang dipakai rata-rata masih menggunakan suspensi standar untuk kendaraannya. Pada aspek pola pengendara dalam mengendarai kendaraan bermotor cukup banyak yang memacu dalam kecepatan lebih saat menuruni jalanan yang memiliki kontur patahan tersebut.

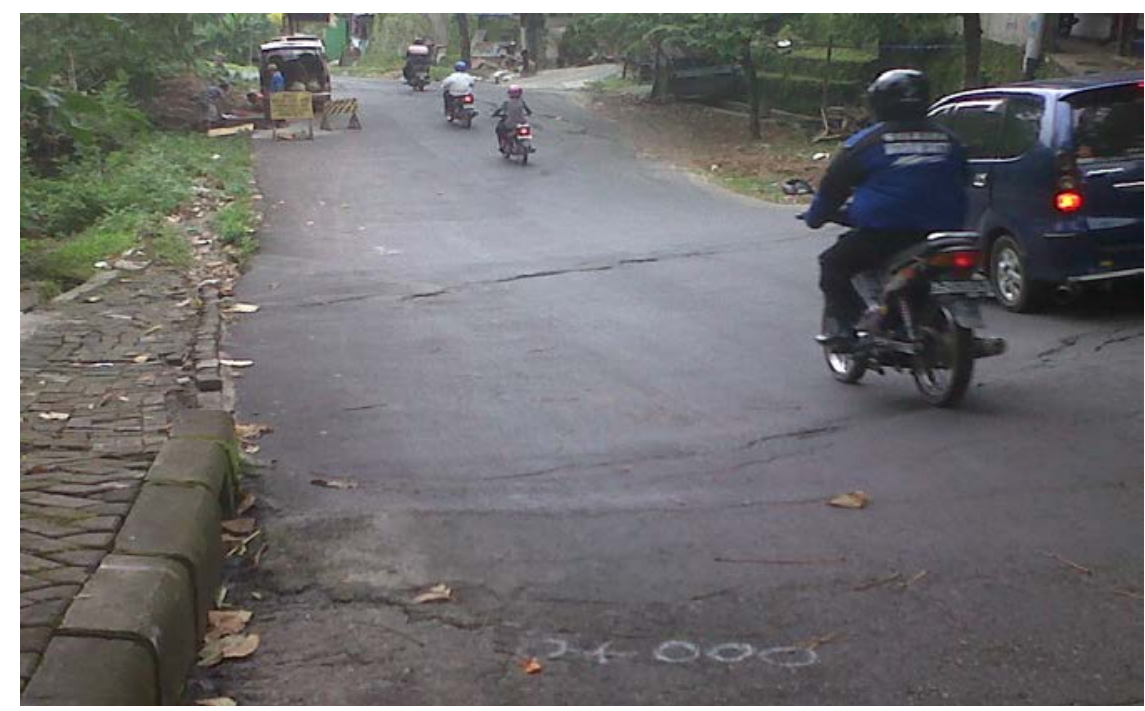

Gambar 4. Patahan di jalan gombel lama Kota Semarang.

Potensi SCI ini kadang menjadi semakin besar dengan pola penanganan kondisi patahan oleh dinas terkait yang kurang tepat. Pola menutup patahan yang terkesan seadanya ternyata masih menimbulkan potensi bahaya SCI. Bagi kendaraan seperti mobil kadangkala sudah tidak begitu menjadi masalah namun untuk sepeda motor masih sangat terasa hentakan yang muncul akibat patahan. Seringkali didapati di beberapa akses jalan, kondisi patahan kadangkala dibiarkan menjadi sangat ekstrim baru kemudian dilakukan proses penanganan.

Dengan melihat apa yang telah diuraikan diatas bahwa sebagai jalur utama untuk aktivitas harian warga Kota Semarang dari segala usia dan dominan dengan kendaraan roda dua, aktivitas orang dan barang yang begitu padat maka akses pada jalan tersebut harus tetap dijaga agar selalu kondusif. Potensi kemiringan jalan dan potensi patahan jalan adalah ancaman yang sangat serius.

Tujuan penulisan artikel ini adalah untuk mendapatkan gambaran riil dari simulasi software tentang fenomena yang terjadi ketika kendaraan melewati patahan secara menurun baik terhadap komponen kendaraan itu sendiri dan pengendara. Mengetahui pengaruh variasi kecepatan dalam menuruni daerah patahan terhadap nilai beban kejut yang akan diteruskan ke pengendara. Serta mengetahui pengaruh variasi ketinggian patahan dan kecepatan kendaraan terhadap beban kejut yang akan diteruskan ke pengendara. Mengetahui batas aman anatara nilai kecepatan dan ketinggian patahan yang bisa diambil agar terhindar dari bahaya cedera tulang belakang.

\section{Metode penelitian}

Penelitian pengaruh patahan jalan dan kecepeatan kendaraan terhadap potensi cedera punggung ini dilakukan dengan metode simulasi menggunakan software analisis FEM. Sampel yang digunakan adalah model sepeda motor jenis suspensi tunggal (monoshock). Data input yang diamasukkan didapat dari berbagai literatur yang relevan, disertai dengan studi kasus langsung di lapangan. Adapaun data input yang dibutuhkan adalah data spesifikasi kendaraan bermotor, khususnya mengenai sistem suspensi. Data kondisi jalan juga digunakan untuk mengkondisikan simulasi seperti keadaan aslinya. Output yang dituju dalam penelitian ini adalah didapatkannya hasil simulasi berupa gaya reaksi yang sampai pada punggung pengendara kendaraan. Diagram alir penelitian dijelaskan pada Gambar 5.

Studi lapangan dilakukan untuk mengetahui secara langsung kondisi jalan yang akan diteliti. Hal ini dilakukan untuk mendapatkan data input yang diperlukan dalam penelitian. Data yang diambil adalah tinggi patahan jalan, yaitu sebesar $10 \mathrm{~cm}$ hingga $40 \mathrm{~cm}$. Sementara kemiringan jalan diamati mencapai sekitar 35 derajat. Dengan kecepatan kendaraan yang melewati jalan tersebut antara 30-60 km/jam.

Material yang digunakan menggunakan material yang digunakan pada sepeda motor pada umumnya. Hal ini dilakukan agar percobaan menggunakan software mendapat hasil yang mirip dengan kondisi asli. Dari sampel sepeda motor yang telah didesain, selanjutnya dilakukan perhitungan menggunakan kinetika untuk mendapatkan gaya yang berlaku pada roda sepeda motor ketika melewati patahan jalan. Dengan menggunakan rumus energi yaitu:

$$
U_{1-2}=\Delta T
$$


Norman Iskandar \& Ikhsan Muhammad R., Pengaruh Tinggi Patahan Jalan dan Kecepatan Kendaraan Terhadap Potensi Cedera Tulang Belakang Pada Pengendara Sepeda Motor

$$
m g h=1 / 2 m\left(v_{2}^{2}-v_{1}^{2}\right)
$$

Diperoleh nilai kecepatan seepeda motor ketika samapai di permukaan bawah patahan. Hasil yang didapat tersebut akan digunakan untuk mencari gaya normal permukaan jalan terhadap sepeda motor menggunakan metode impuls-momentum [7].

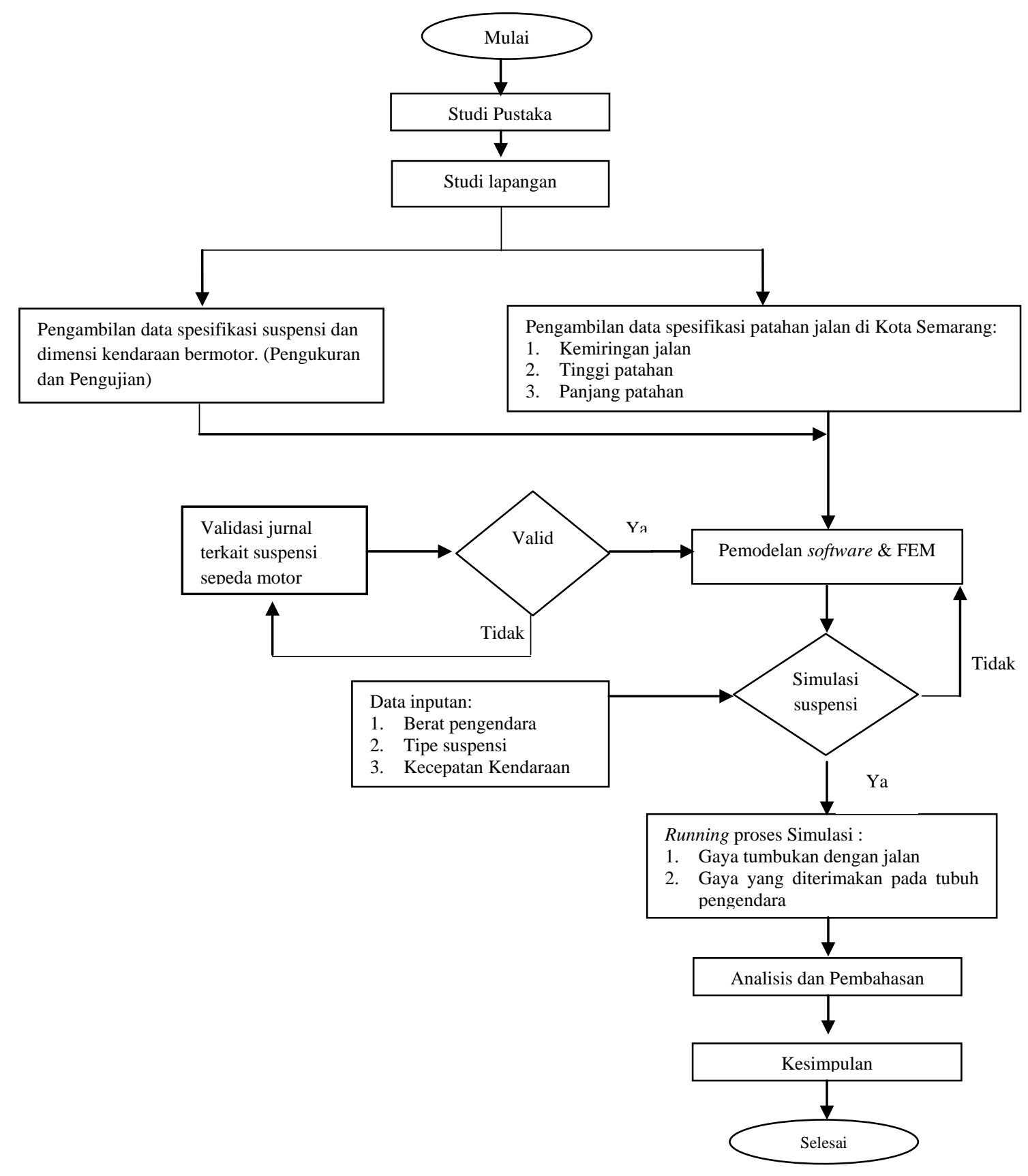

Gambar 5. Diagram alir.

Setelah didapat besar gaya masukan untuk simulasi, langkah selanjutnya adalah membuat mesh pada model sepeda motor. Proses ini perlu dlakukan agar simulasi mungkin dilakukan. Kepadatan mesh dipilih pada daerah lengan roda, lengan ayun dan pegas sepeda motor. Gambar 7 menunjukkan hasil pembuatan mesh pada model. Penyederhanaan model juga dilakukan sehingga simulasi yang akan dilakukan tidak memakan terlalu banyak sumber daya. Model akan dipotong lokal pada bagian sisstem suspensi hingga tempat duduk pengemudi.

Langkah yang dilakukan selanjutnya adalah pemodelan gaya yang bekerja pada kendaraan. Pada roda diterapkan gaya kontak dengan jalanan sebesar sesuai hasil perhitungan $\mathrm{N}$ sebelumnya. Sementara untuk memberikan efek kepegasan, sambungan shockbreaker akan dimasukkan informasi nilai koefisien kepegasan sebesar 6800 N/m. bagian 
depan yang tidak ikut dilakukan simulasi akan dianggap sebagai sistem rigid. Untuk lebih jelasnya dapat dilihat pada Gambar 8.

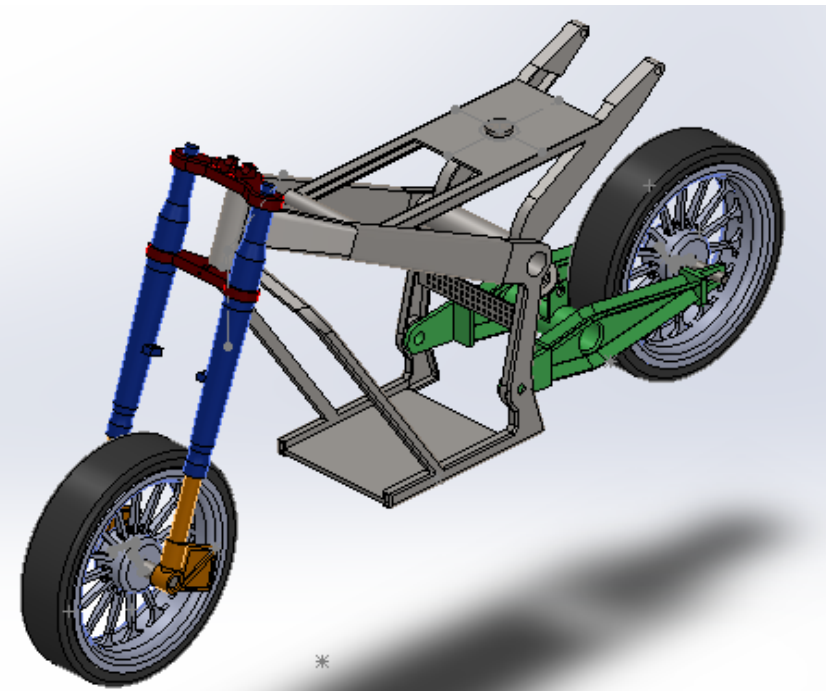

Gambar 6. Sepeda motor sampel

$$
\begin{gathered}
G_{1}+\int_{t 1}^{t 2} F \cdot d t=G_{2} \\
m v_{1}+(N-m g) t=m v_{2}
\end{gathered}
$$

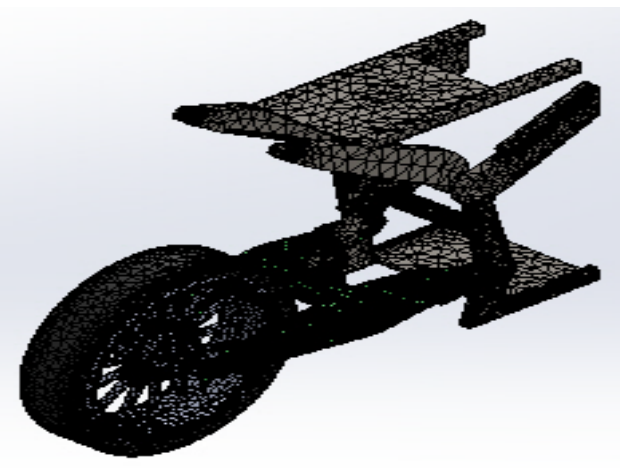

Gambar 7. Hasil pembuatan mesh.

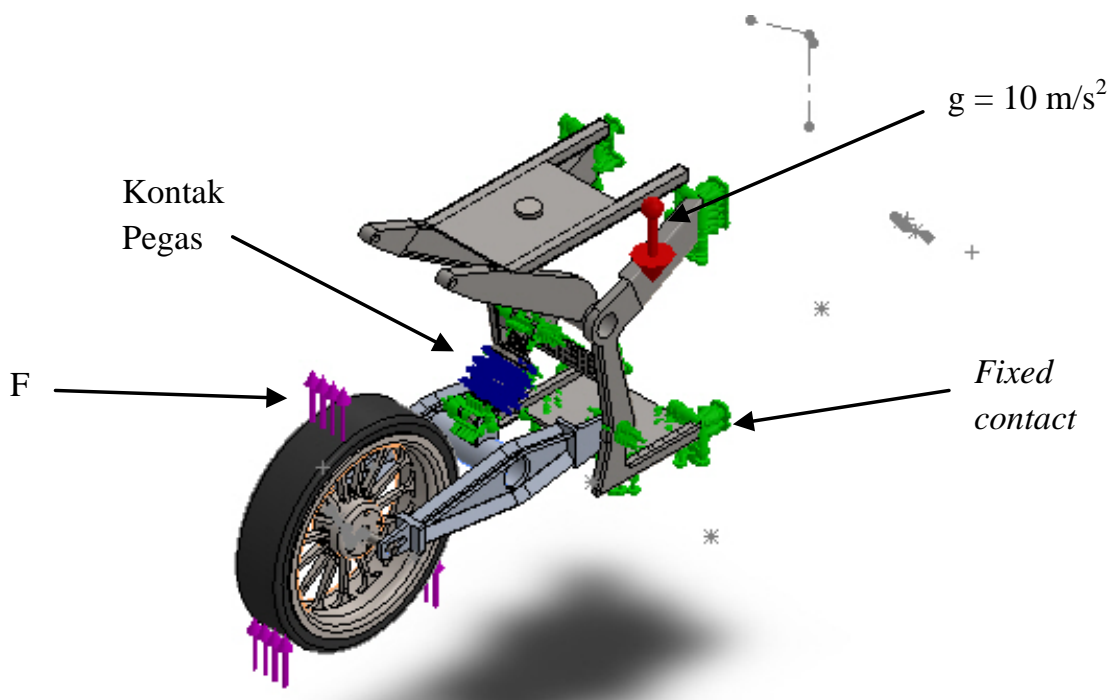

Gambar 8. Pemodelan gaya 
Hasil simulasi dapat dilihat setelah simulasi dijalankan, sementara output yang dicari adalah besar gaya reaksi yang terjadi pada tubuh pengendara. Hasil ini nantinya akan dihubungkan dengan data masukan berupa tinggi patahan jalan dan kecepatan sepeda motor untuk diketahui pengaruhnya.

\section{Hasil dan pembahasan}

Hasil percobaan menggunakan software disajikan dalam tabel dan grafik sebagai berikut:

Tabel 1. Besar gaya normal tiap variabel tinggi patahan jalan pada $\mathrm{v}=20 \mathrm{~km} / \mathrm{jam}$.

\begin{tabular}{cccccccc}
\hline $\begin{array}{c}\mathrm{H} \\
(\mathrm{m})\end{array}$ & $\begin{array}{c}\mathrm{t} \\
(\mathrm{s})\end{array}$ & $\begin{array}{c}\mathrm{V}_{1} \\
(\mathrm{~m} / \mathrm{s})\end{array}$ & $\begin{array}{c}\mathrm{X} \\
(\mathrm{m})\end{array}$ & $\begin{array}{c}\mathrm{G}_{1} \\
(\mathrm{~kg} . \mathrm{m} / \mathrm{s})\end{array}$ & $\begin{array}{c}\mathrm{V}_{2} \\
(\mathrm{~m} / \mathrm{s})\end{array}$ & $\begin{array}{c}\mathrm{G}_{2} \\
(\mathrm{~kg} . \mathrm{m} / \mathrm{s})\end{array}$ & $\begin{array}{c}\mathrm{N} \\
(\mathrm{N})\end{array}$ \\
\hline 0.1 & 0.14 & 5.56 & 0.79 & 1112 & 16.73 & 1146.745 & 2205.34 \\
0.2 & 0.20 & 5.56 & 1.12 & 1112 & 16.79 & 1180.468 & 2301.07 \\
0.3 & 0.25 & 5.56 & 1.37 & 1112 & 16.84 & 1213.253 & 2371.42 \\
0.4 & 0.28 & 5.56 & 1.59 & 1112 & 16.90 & 1245.176 & 2428.35 \\
0.5 & 0.32 & 5.56 & 1.77 & 1112 & 16.96 & 1276.301 & 2476.61 \\
\hline
\end{tabular}

Tabel 2. Besar gaya normal tiap variabel tinggi patahan jalan pada $\mathrm{v}=60 \mathrm{~km} / \mathrm{jam}$.

\begin{tabular}{cccccccc}
\hline $\begin{array}{c}\mathrm{H} \\
(\mathrm{m})\end{array}$ & $\begin{array}{c}\mathrm{t} \\
(\mathrm{s})\end{array}$ & $\begin{array}{c}\mathrm{V}_{1} \\
(\mathrm{~m} / \mathrm{s})\end{array}$ & $\begin{array}{c}\mathrm{X} \\
(\mathrm{m})\end{array}$ & $\begin{array}{c}\mathrm{G}_{1} \\
(\mathrm{~kg} . \mathrm{m} / \mathrm{s})\end{array}$ & $\begin{array}{c}\mathrm{V}_{2} \\
(\mathrm{~m} / \mathrm{s})\end{array}$ & $\begin{array}{c}\mathrm{G}_{2} \\
(\mathrm{~kg} . \mathrm{m} / \mathrm{s})\end{array}$ & $\begin{array}{c}\mathrm{N} \\
(\mathrm{N})\end{array}$ \\
\hline 0.1 & 0.14 & 16.67 & 2.38 & 3334 & 16.73 & 3345.75 & 2044.28 \\
0.2 & 0.20 & 16.67 & 3.37 & 3334 & 16.79 & 3357.46 & 2078.16 \\
0.3 & 0.25 & 16.67 & 4.12 & 3334 & 16.84 & 3369.12 & 2104.02 \\
0.4 & 0.28 & 16.67 & 4.76 & 3334 & 16.90 & 3380.75 & 2125.71 \\
0.5 & 0.32 & 16.67 & 5.32 & 3334 & 16.96 & 3392.34 & 2144.72 \\
\hline
\end{tabular}

Tabel 1 hingga 3 menampilkan hasil perhitungan yang telah dilakukan menggunakan persamaan penyelesaian masalah kinetika metode energi, dan persamaan impuls-momentum. Perhitungan ini dilakukan menggunakan 3 variabel kecepatan, yaitu pada 20 km/jam, 60 km/jam dan 100 km/jam. Tiap besar kecepatan tersebut divariasikan tinggi patahan jalan pada $10 \mathrm{~cm}$ hingga $50 \mathrm{~cm}$. Hasil yang didapat adalah, pada kecepatan yang sama, semakin tinggi patahan jalan maka semakin besar gaya yang menghantam sepeda motor.

Sementara perubahan kecepatan pada ketinggian patahan yang sama menimbulkan efek yang berbeda pada besar gaya reaksi. Tabel 4 sampai 6 menunjukkan hubungan antara kecepatan kendaraan dengan besar gaya reaksi pada ketinggian patahan sebagai berikut.

Tabel 3. Besar gaya normal tiap variabel tinggi patahan jalan pada v $=100 \mathrm{~km} / \mathrm{jam}$.

\begin{tabular}{cccccccc}
\hline $\begin{array}{c}\mathrm{H} \\
(\mathrm{m})\end{array}$ & $\begin{array}{c}\mathrm{t} \\
(\mathrm{s})\end{array}$ & $\begin{array}{c}\mathrm{V}_{1} \\
(\mathrm{~m} / \mathrm{s})\end{array}$ & $\begin{array}{c}\mathrm{X} \\
(\mathrm{m})\end{array}$ & $\begin{array}{c}\mathrm{G}_{1} \\
(\mathrm{~kg} . \mathrm{m} / \mathrm{s})\end{array}$ & $\begin{array}{c}\mathrm{V}_{2} \\
(\mathrm{~m} / \mathrm{s})\end{array}$ & $\begin{array}{c}\mathrm{G}_{2} \\
(\mathrm{~kg} . \mathrm{m} / \mathrm{s})\end{array}$ & $\begin{array}{c}\mathrm{N} \\
(\mathrm{N})\end{array}$ \\
\hline 0.1 & 0.14 & 27.78 & 3.97 & 5555.55 & 27.81 & 5562.61 & 2011.44 \\
0.2 & 0.20 & 27.78 & 5.61 & 5555.55 & 27.85 & 5569.66 & 2031.87 \\
0.3 & 0.25 & 27.78 & 6.87 & 5555.55 & 27.88 & 5576.70 & 2047.52 \\
0.4 & 0.28 & 27.78 & 7.93 & 5555.55 & 27.92 & 5583.73 & 2060.68 \\
0.5 & 0.32 & 27.78 & 8.87 & 5555.55 & 27.95 & 5590.76 & 2072.26 \\
\hline
\end{tabular}


Tabel 4. Besar gaya normal tiap variable kecepatan, pada tinggi patahan $0.05 \mathrm{~m}$

\begin{tabular}{cccccccc}
\hline $\begin{array}{c}\mathrm{H} \\
(\mathrm{m})\end{array}$ & $\begin{array}{c}\mathrm{T} \\
(\mathrm{s})\end{array}$ & $\begin{array}{c}\mathrm{V}_{1} \\
(\mathrm{~m} / \mathrm{s})\end{array}$ & $\begin{array}{c}\mathrm{X} \\
(\mathrm{m})\end{array}$ & $\begin{array}{c}\mathrm{G}_{1} \\
(\mathrm{~kg} . \mathrm{m} / \mathrm{s})\end{array}$ & $\begin{array}{c}\mathrm{V}_{2} \\
(\mathrm{~m} / \mathrm{s})\end{array}$ & $\begin{array}{c}\mathrm{G}_{2} \\
(\mathrm{~kg} . \mathrm{m} / \mathrm{s})\end{array}$ & $\begin{array}{c}\mathrm{N} \\
(\mathrm{N})\end{array}$ \\
\hline 0.05 & 0.10 & 5.55 & 0.56 & 1111.11 & 5.64 & 1128.63 & 2135.52 \\
0.05 & 0.10 & 11.11 & 1.12 & 2222.22 & 11.15 & 2231.03 & 2049.27 \\
0.05 & 0.10 & 16.66 & 1.68 & 3333.33 & 16.70 & 3339.21 & 2020.25 \\
0.05 & 0.10 & 22.22 & 2.24 & 4444.44 & 22.24 & 4448.85 & 2005.70 \\
0.05 & 0.10 & 27.77 & 2.804547 & 5555.55 & 27.79541 & 5559.082 & 1996.968 \\
\hline
\end{tabular}

Tabel 5. Besar gaya normal tiap variable kecepatan, pada tinggi patahan $0.25 \mathrm{~m}$

\begin{tabular}{ccccccccc}
\hline $\begin{array}{c}\mathrm{H} \\
(\mathrm{m})\end{array}$ & $\begin{array}{c}\mathrm{T} \\
(\mathrm{s})\end{array}$ & $\begin{array}{c}\mathrm{V}_{1} \\
(\mathrm{~m} / \mathrm{s})\end{array}$ & $\begin{array}{c}\mathrm{X} \\
(\mathrm{m})\end{array}$ & $\begin{array}{c}\mathrm{G}_{1} \\
(\mathrm{~kg} . \mathrm{m} / \mathrm{s})\end{array}$ & $\begin{array}{c}\mathrm{V}_{2} \\
(\mathrm{~m} / \mathrm{s})\end{array}$ & $\begin{array}{c}\mathrm{G}_{2} \\
(\mathrm{~kg} . \mathrm{m} / \mathrm{s})\end{array}$ & $\begin{array}{c}\mathrm{N} \\
(\mathrm{N})\end{array}$ \\
\hline 0.25 & 0.23 & 5.55 & 1.25 & 1111.11 & 5.98 & 1196.15 & 2338.66 \\
0.25 & 0.23 & 11.11 & 2.51 & 2222.22 & 11.33 & 2265.94 & 2155.63 \\
0.25 & 0.23 & 16.66 & 3.76 & 3333.33 & 16.81 & 3362.63 & 2091.79 \\
0.25 & 0.23 & 22.22 & 5.02 & 4444.44 & 22.33 & 4466.46 & 2059.53 \\
0.25 & 0.23 & 27.77 & 6.27 & 5555.55 & 27.87 & 5573.18 & 2040.09 \\
\hline
\end{tabular}

Tabel 6. Besar gaya normal tiap variable kecepatan, pada tinggi patahan $0.5 \mathrm{~m}$

\begin{tabular}{ccccccccc}
\hline $\begin{array}{c}\mathrm{H} \\
(\mathrm{m})\end{array}$ & $\begin{array}{c}\mathrm{T} \\
(\mathrm{s})\end{array}$ & $\begin{array}{c}\mathrm{V}_{1} \\
(\mathrm{~m} / \mathrm{s})\end{array}$ & $\begin{array}{c}\mathrm{X} \\
(\mathrm{m})\end{array}$ & $\begin{array}{c}\mathrm{G}_{1} \\
(\mathrm{~kg} . \mathrm{m} / \mathrm{s})\end{array}$ & $\begin{array}{c}\mathrm{V}_{2} \\
(\mathrm{~m} / \mathrm{s})\end{array}$ & $\begin{array}{c}\mathrm{G}_{2} \\
(\mathrm{~kg} . \mathrm{m} / \mathrm{s})\end{array}$ & $\begin{array}{c}\mathrm{N} \\
(\mathrm{N})\end{array}$ \\
\hline 0.5 & 0.32 & 5.55 & 1.77 & 1111.11 & 6.378 & 1275.53 & 2476.96 \\
0.5 & 0.32 & 11.11 & 3.55 & 2222.22 & 11.54 & 2308.82 & 2233.25 \\
0.5 & 0.32 & 16.66 & 5.32 & 3333.33 & 16.96 & 3391.68 & 2144.75 \\
0.5 & 0.32 & 22.22 & 7.09 & 4444.44 & 22.44 & 4488.37 & 2099.59 \\
0.5 & 0.32 & 27.77 & 8.87 & 5555.55 & 27.95 & 5590.76 & 2072.26 \\
\hline
\end{tabular}

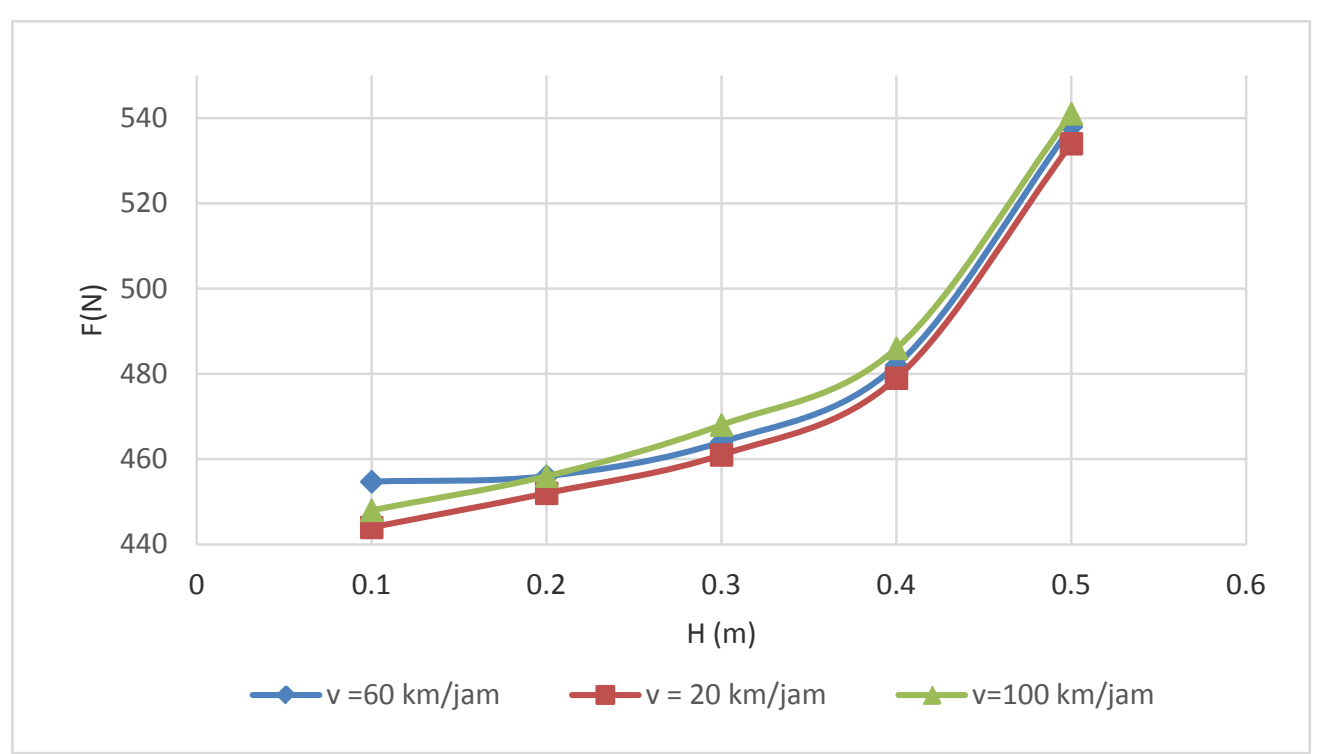

Gambar 9. Grafik hubungan gaya yang berlaku pada pengendara sepeda motor dengan variabel tinggi patahan jalan. 
Tabel 4 hingga 6 menampilkan hasil perhitungan yang telah dilakukan menggunakan persamaan penyelesaian masalah kinetika metode energi, dan persamaan impuls-momentum. Perhitungan ini dilakukan menggunakan 3 variabel tinggi patahan jalan, yaitu pada $5 \mathrm{~cm}, 25 \mathrm{~cm}$ dan $50 \mathrm{~cm}$. Tiap besar patahan jalan tersebut divariasikan kecepatan kendaraan pada $20 \mathrm{~km} / \mathrm{jam}$ hingga $100 \mathrm{~km} / \mathrm{jam}$. Hasil yang didapat adalah, pada tinggi patahan yang sama, semakin besar kecepatan maka semakin kecil gaya yang menghantam sepeda motor.

Gambar 9 menunjukkan hubungan antara variasi tinggi patahan jalan terhadap besar gaya yang dialami pengendara sepeda motor pada kecepatan yang sama pada variasi 20 km/jam, 60 km/jam dan 100 km/jam. Grafik memperlihatkan adanya tren kenaikan gaya yang dialami oleh pengendara sepeda motor seiring naiknya tinggi patahan jalan.

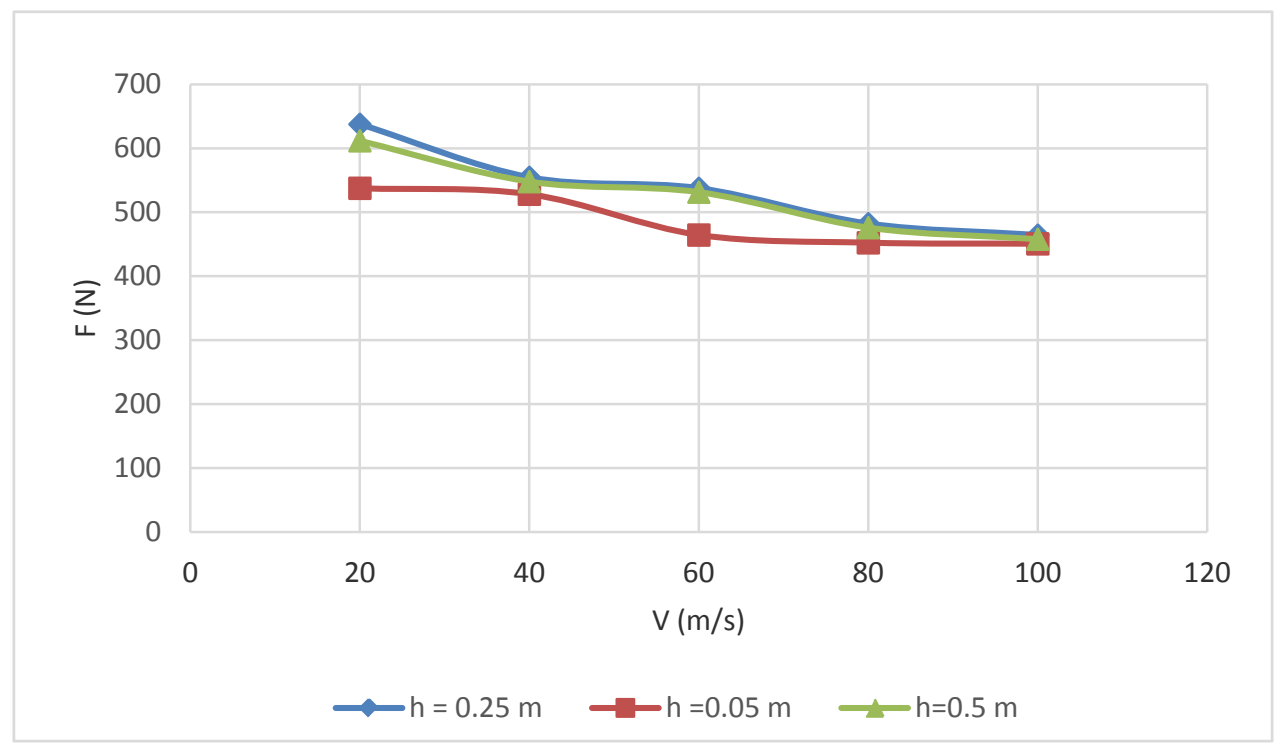

Gambar 10. Grafik hubungan gaya yang berlaku pada pengendara sepeda motor dengan variabel kecepatan kendaraan.

Gambar 10 menunjukkan hubungan antara variasi kecepatan kendaraan terhadap besar gaya yang dialami pengendara sepeda motor pada tinggi patahan jalan yang sama yaitu variasi $0.05 \mathrm{~m}, 0.25 \mathrm{~m}$ dan $0.5 \mathrm{~m}$. Grafik memperlihatkan adanya tren penurunan gaya yang dialami oleh pengendara sepeda motor seiring naiknya tinggi patahan jalan.

Tabel 7. Properti mekanis tulang manusia [8].

\begin{tabular}{lll}
\hline & Compression & Tension \\
\hline Wet apparent density $\left(\mathrm{g} / \mathrm{cm}^{3)}\right.$ & $0.017 \pm 0.04$ & $0.19 \pm 0.04$ \\
Modulus $(\mathrm{MPa})$ & $291 \pm 113$ & $301 \pm 100$ \\
Yield strain $(\%)$ & $0.84 \pm 0.06$ & $0.78 \pm 0.04$ \\
Ultimate Strain $(\%)$ & $1.45 \pm 0.33$ & $1.59 \pm 0.33$ \\
Yield Stress $(\mathrm{MPa})$ & $1.92 \pm 0.84$ & $1.75 \pm 0.65$ \\
Ultimate Stress $(\mathrm{MPa})$ & $2.23 \pm 0.95$ & $2.23 \pm 0.76$ \\
\hline
\end{tabular}

Tabel 8. Siklus rata-rata yang dialami struktur tulang belakang manusia sebelum mengalami kegagalan pada setiap besar sudut postur.

\begin{tabular}{cccc}
\hline Kelompok Usia & $0^{\circ}$ & $22.5^{\circ}$ & $45^{\circ}$ \\
\hline Spesimen tua & 8267 & 3261 & 263 \\
Spesimen lebih muda & 1020 & 7124 & 3929 \\
\hline
\end{tabular}

Sama seperti material lain, tulang manusia memiliki properti mekanis tersendiri. Properti mekanis ini menunjukkan bagaimana karakteristik tulang manusia. Properti mekanis dapat dilihat pada Tabel 7. Susunan tulang belakang manusia mampu menahan gaya hantaman berkisar dari $650 \mathrm{~N}$ hingga 6431 sebelum terjadinya kerusakan atau cidera. Sementara respon tulang berbeda tergantung seberapa tua umur manusia. Mekanisme kerusakan dan lokasinya bervariasi pada masing-masing usia. Semakin tua usia pengemudi, semakin besar kemungkinan struktur tulang terdegradasi, dan kemungkinan cidera semakin besar [9]. Pada penelitian yang dilakukan oleh Sean Gallagher dkk, menguji ketahanan tulang manusia terhadap pembebanan berulang. Penelitian ini menguji berapa banyak siklus yang mampu dilalui struktur tulang belakang ketika dilakukan pembebanan berulang sebelum terjadi kegagalan [10]. 
Variabel yang digunakan adalah posisi postur tulang belakang, mulai dari tegak, membentuk sudut $22.5^{\circ}$ dan $45^{\circ}$. Pembebanan diberikan sebesar $500 \mathrm{~N}, 750 \mathrm{~N}$ dan $1050 \mathrm{~N}$ tergantung pada postur struktur tulang belakang. Laju pembebanan adalah 1 siklus tiap waktu 3 detik. Dengan hasilnya ditunjukkan oleh Tabel 8.

\section{Kesimpulan}

Pada kasus sepeda motor suspensi tunggal, ketika menuruni patahan dengan ketinggian $0.1 \mathrm{~m}$ hingga $0.5 \mathrm{~m}$ dengan kecepatan yang sama yaitu variasi $20 \mathrm{~km} / \mathrm{jam}, 60 \mathrm{~km} / \mathrm{jam}$ dan $100 \mathrm{~km} / \mathrm{jam}$, gaya yang dialami pengendara sepeda motor meningkat seiring bertambahnya tinggi patahan jalan. Sementara pada kasus sepeda motor suspensi tunggal, ketika menuruni patahan dengan kecepatan 20 km/jam hingga 100 km/jam dengan tinggi patahan yang sama yaitu variasi $0.05 \mathrm{~m}, 0.25 \mathrm{~m}$ dan $0.5 \mathrm{~m}$, gaya yang dialami pengendara sepeda motor menurun seiring meningkatnya kecepatan. Gaya hantaman maksimal yang terjadi pada percobaan adalah sebesar $637 \mathrm{~N}$, angka ini masih di bawah besar gaya yang dibutuhkan untuk mengalami fraktur, yaitu 650 N. Tetapi ada tren kenaikan disebabkan oleh bertambahnya tinggi patahan dan kecepatan kendaraan, sehingga risiko cedera tetap tinggi. Pada siklus yang berulang, risiko cedera akan meningkat karena adanya kemungkinan tulang mengalami kegagalan lelah. Dengan posisi duduk tegak, tulang manusia dapat mengalami kegagalan pada sekitar 8000 siklus. Pada posisi menekuk sebesar 22.5 derajat kemungkinan terjadi gagal setelah 3000 siklus, dan pada posisi menunduk sebesar 45 derajat siklus gagalnya mencapai 267 siklus. Kondisi ini memiliki potensi cedera pada pengendara sepeda motor yang rutin melewati patahan jalan ketika beraktivitas.

\section{Referensi}

[1] Luthfi Gatam, 2012, Salah Posisi saat bawa motor juga bisa picu cedera punggung, www.health.detik.com, (diakses 28 Februari 2016 pukul 13.37).

[2] www.jebailylaw.com (diakses 28 februari 2016 pukul 13.10 WIB).

[3] www.pinterest.com (diakses 28 februari 2016 pukul 14.05 WIB).

[4] www.jebailylaw.com (diakses 28 februari 2016 pukul 13.10 WIB)

[5] www.neuros.net (diakses 28 februari 2016 pukul 13.30 WIB)

[6] www.sonicspring.com (diakses 10 Oktober 2016 pukul 18.05)

[7] Meriam, J.L. 2008. Engineering Mechanics Dynamics $6^{\text {th }}$ Ed, John Wiley \& Sons.

[8] Saha, S., Hayes, W.C., 2014. Tensile Impact Properties of Human Compact Bone. Journal Biomechanics Vol.9 243-251.

[9] Voo, L. M., et al, 1998. Biomechanical impact tolerance characteristic of the human neck. In : Proceedings of the 16th International Technical Conference on the Enhanced Safety of Vehicles (ESV)

[10] Gallagher, S., et al, 2007. A Comparison of Fatigue Failure Responses of Old Versus Middle-Aged Lumbar Motion Segments in Simulated Flexed Lifting. Jornal of Biomechanics Vol. 32, 1832-1839. 